\title{
Тепловизионное исследование сорбционных и каталитических процессов на поверхности твердого тела
}

\section{Вайнер Б.Г. ${ }^{1,2}$}

\author{
${ }^{1}$ ИФП СО РАН, 630090, Новосибирск, пр. Ак. Лаврентьева, 13 \\ ${ }^{2}$ Новосибирский государственныій университет, 630090, Новосибирск, ул. Пирогова, 2
}

DOI 10.34077/Semicond2019-92

К настоящему времени предложено большое число методов исследования поверхности твердых тел. Получаемые с их помощью результаты представляют не только академический интерес, но имеют также важное прикладное значение, в частности, потому, что поверхностные свойства твердого тела могут проявляться по-разному в разных условиях, в которых твердотельные системы используют на практике. Отдельный круг вопросов затрагивает проблему взаимодействия твердой поверхности с ее газовым окружением. Молекулы газовой среды приводят к физической адсорбции, обеспечивающей в специальных случаях протекание каталитических и других химических реакций на границе раздела фаз. В свою очередь, в обычных внешних условиях ведущее значение в этих процессах принадлежит взаимодействию поверхности тела с парами воды, которые, как правило, всегда присутствуют в окружающей среде.

Изучение особенностей сорбционных свойств поверхности твердых тел, помещенных в разные газовые среды, трудно переоценить. В то же время, практика показывает, что при решении этой проблемы экспериментаторы обычно вполне довольствуются весьма ограниченным стандартным набором методов исследования, среди которых можно упомянуть термодесорбцию, измерение изотерм адсорбции и др. Методы, обеспечивающие прямую визуализацию физико-химических процессов, протекающих на поверхности в реальном времени, в том числе, количественный анализ тепловых изображений таких процессов, до сих пор в данной области практически не применяют.

Нами было показано, что тепловидение нового поколения представляет собой эффективный инструмент исследования сорбционных процессов и каталитических реакций, протекающих при взаимодействии газов с твердыми телами [1-4].

В докладе подробно представлена новая оригинальная методика, позволяющая в автоматическом режиме по запланированной программе эксперимента проводить прецизионные исследования сорбционно-каталитических процессов с возможностью одновременной подачи разных газов к библиотекам, составленным сразу из нескольких разнотипных образцов. На количественном уровне продемонстрировано, что поверхностные термодинамические свойства твердотельных систем могут существенно различаться. Это надежно выявлено с помощью матричного тепловизионного метода при измерении поверхностных температурных полей с частотой $\sim 100$ кадров в секунду. На

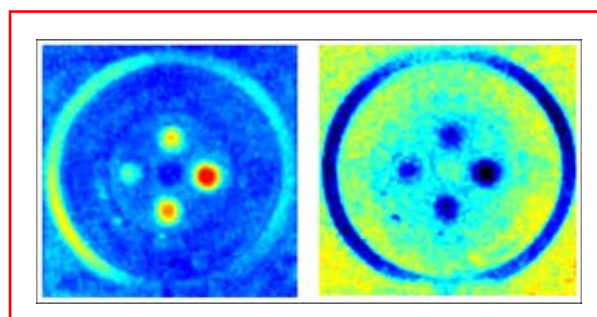

Puc.1. Термограммы библиотеки из четырех высокодисперсных алюмосиликатных образиов $\left(\mathrm{SiO}_{2} / \mathrm{Al}_{2} \mathrm{O}_{3}\right)$, модифичированных солями Со и Се с разным прочентным содержанием металлов. рис. 1 приведен пример термограмм библиотеки из разных по составу структур в режиме адсорбции (слева) и десорбции (справа) $\mathrm{H}_{2} \mathrm{O}$.

Работа выполнена при финансовой поддержке РФФИ, грант № 18-08-00956.

[1] B.G.Vainer, J. Phys. D: Appl. Phys., 41, 065102 (2008).

[2] M.S.Mel'gunov et al., Adsorption, 19, 835 (2013).

[3] B.G.Vainer, In: RCCT-2017 (26-30.06.2017, Novosibirsk), Novosibirsk: NIIC SB RAS, 56 (2017).

[4] Б.Г.Вайнер и др., В сб.: ХХХVI Всер. симп. мол. ученых по хим. кин. (2. Москва, 18-21.03.2019). Москва: МГУ им. М.В.Ломоносова. Хим. фак., 96 (2019). 